\title{
Mechanical characterization of HDPE reinforced with cellulose from rice husk biomass
}

\author{
Mariane Weirich Bosenbecker1, Gabriel Monteiro Cholant¹, Gabriela Escobar Hochmuller da Silva1, \\ Oscar Giordani Paniz ${ }^{1}$, Neftali Lenin Villarreal Carreño ${ }^{1}$, Juliano Marini and Amanda Dantas de Oliveira ${ }^{1 *}$ (C) \\ ${ }^{1}$ Centro de Desenvolvimento Tecnológico - CDTec, Universidade Federal de Pelotas - UFPel, \\ Pelotas, RS, Brasil \\ ${ }^{2}$ Departamento de Engenharia de Materiais - DEMa, Universidade Federal de São Carlos - UFSCar, \\ São Carlos, SP, Brasil \\ *amandaoliveira82@gmail.com
}

\begin{abstract}
High-density polyethylene (HDPE) reinforced with cellulose from rice husk (RH) were prepared and studied. The RH biomass was submitted to acid extraction and bleaching process and then analyzed for its cellulose extraction efficiency by X-ray diffraction (XRD) and Fourier transformation infrared spectroscopy (FTIR). After that, the RH cellulose (RHC) was incorpored to the HDPE matrix by melt blending with different filler contents (5, 10 and $15 \mathrm{wt} \%$ ), and then characterized in terms of mechanical properties and morphology. The RHC incorporation in the HDPE matrix resulted in an increase in elastic modulus regardless the filler content added; also, the impact resistance was maintained for RHC contents up to $10 \%$. The morphological analysis of the composites showed that the cellulose was well dispersed in the matrix, which contributed to the improvement of the final rigidity of these materials, indicating the feasibility of incorporating this residue in the production of HDPE composites.
\end{abstract}

Keywords: cellulose, biomass, polymeric composites, rice husk.

How to cite: Bosenbecker, M. W., Cholant, G. M., Silva, G. E. H., Paniz, O. G., Carreño, N. L. V., Marini, J., \& Oliveira, A. D. (2019). Polimeros: Ciência e Tecnologia, 29(4), e2019058. https://doi.org/10.1590/0104-1428.04819

\section{Introduction}

Polymeric composites reinforced with vegetable fibers have been the target of great academic and industrial interest for replacing, generally with cost advantages and lightness, materials made of conventional polymeric composites. These composites are less aggressive and toxic, since they are reinforced with raw materials of plant origin, such as oils, starch and cellulose. Besides coming from renewable sources, meeting the requirements of biodegradability and preservation of the environment throughout its cycle of life $\mathrm{f}^{[1]}$, they can be an alternative for the reduction of inappropriate waste disposal when the utilized fibers are from agroindustrial waste ${ }^{[2]}$.

Rice is the most popular food in the world, its importance can be noted by its numbers of consumption and production. The consumption of rice as food for 2017 was estimated at $53.7 \mathrm{~kg} /$ person. To meet this demand, rice production forecasts, for the same year, were estimated at 759.6 million tonnes according to the Food and Agriculture Organization $(\mathrm{FAO})^{[3]}$. In this context, the Brazilian production of rice is in the order of 12 million tons/year and the state of Rio Grande do Sul represents $60 \%$ of this production ${ }^{[4]}$. For each ton of rice produced, it is estimated that 0.23 ton of $\mathrm{RH}$ are formed during the rice refining process, being the most voluminous by-product ${ }^{[5]}$. In this way, RH is an agroindustrial large quantity residue in Rio Grande do Sul.
The average chemical composition of RH is defined in $35 \%$ cellulose, $25 \%$ hemicellulose, $20 \%$ lignin and $20 \%$ of others ${ }^{[6]}$. It is important to note that these contents may vary significantly according to type of paddy, crop year, climatic and geographical conditions and sample preparation for analysis.

These peels have low commercial value because the contained silica $\left(\mathrm{SiO}_{2}\right)$ and the fibers do not have nutritional value, therefore they are not used in human or animal feeding. The destination found for the $\mathrm{RH}$, in the last years, has been the discharge into crops and river bottoms, resulting in serious environmental impacts. In other cases, $\mathrm{RH}$ has been used as a source of energy for parboiling, but it is also a problem as it contributes to air pollution.

Polymeric composites using cellulose as reinforcing agent have several advantages, generally these natural reinforcements are lighter, more economically attractive and provide greater resistance when compared with inorganic reinforcing agents ${ }^{[7]}$. But interestingly, there are no reports on the use of cellulose obtained from RH in HDPE matrix.

Therefore, the objective of this work was to evaluate the use of cellulose extracted from $\mathrm{RH}$ in the obtention of composites with HDPE by melt blending, offering an alternative reuse for this agroindustrial residue. The work 
also aimed to promote an improvement in the mechanical properties of HDPE.

\section{Materials and Methods}

High density polyethylene - HDPE (GM9450F) obtained from Braskem S/A was used as polymeric matrix. The rice hulks were obtained from a cereal supply located in Pelotas/RS - Brazil. All reagents used in this work had analytical grade.

\subsection{Cellulose obtaining from $\mathrm{RH}$}

Figure 1 presents a flowchart of the methodology used for the RHC obtention.

Firstly, the rice hulks were milled in a knife mill (Marconi-Model MA 340). After that, the milled biomass was submitted to the first step treatment which consists in an acid treatment to remove the hemicellulose and lignin present in the RH . The milled RH was added in a solution of water, acetic acid and nitric acid at a ratio of $6: 5: 1 \mathrm{v} / \mathrm{v}$, respectively, under mechanical stirring and reflux at $80^{\circ} \mathrm{C}$ for $4 \mathrm{~h}$. The resulting material was washed and filtered with distilled water untill reached the neutral $\mathrm{pH}$.

The bleaching process was done by the imersion of the resulting material from the first step in a solution of sodium hypochlorite for $24 \mathrm{~h}$. After the steady time, the material was filtered using distilled water untill was neutralized. The non-passing material was the RHC, which was dried at $60^{\circ} \mathrm{C}$ for $24 \mathrm{~h}$.

\subsection{Cellulose characterization}

\subsubsection{X-ray Diffraction (XRD)}

The XRD analyzes were performed using a diffractometer (D8 Advance Bruker) with wavelength of $\chi=1,541 \AA$, operating at $40 \mathrm{KV}$ and $40 \mathrm{~mA}$. The scans were performed in the range of $2 \theta$ between 10 and $50^{\circ}$, at a rate of $1 / \mathrm{min}$.

\subsubsection{Fourier Transformation Infrared Spectroscopy (FTIR)}

The analyses were done using a Spectrum 1000 spectrophotometer from Perkin Elmer, in the range between 400 and $4000 \mathrm{~cm}^{-1}$. Each spectrum corresponds to the average of 10 scans at a resolution of $4 \mathrm{~cm}^{-1}$.

\subsubsection{Scanning Electron Microscopy (SEM) analysis}

The microscopy analyses of the RH in natura, the RH after the first treatment and the RH cellulose were performed by SEM using a Shimadzu, modelo SSX-550 Superscan equipament.

\subsection{HDPE/Cellulose composites preparation}

\subsubsection{Melting blending pocess}

To produce the composites, a single screw extruder (CIOLA, model MEP-18) with $\mathrm{L} / \mathrm{D}=22$ was used. The temperature profile used was $180 / 190^{\circ} \mathrm{C}$ in the two heating zones and $190{ }^{\circ} \mathrm{C}$ for the matrix. The composites were obtained with 5,10 and $15 \mathrm{wt} \%$ by mass of cellulose. The pure polymer also was obtained using the same processing conditions in order to have their results compared to those obtained to the composite materials.

\subsubsection{Composites molding}

The materials obtained from the extrusion process were pelletized and then molded by compression at $200^{\circ} \mathrm{C}$ in a hydraulic press (Marconi, MA098/A) using the following cycle: pre-heating (for $2 \mathrm{~min}$ )/ pressing ( 3 ton for $2 \mathrm{~min}$ )/ relief/pressing ( 5 tons for $2 \mathrm{~min}$ ) / forced cooling in water at room temperature. This process results in plates with $10 \mathrm{~cm}$ of length, $10 \mathrm{~cm}$ of width and $3.2 \mathrm{~mm}$ of thickness. The specimens for tensile and impact mechanical tests were stamped from the plates obtained.

Figure 2 shows a schematic of all the steps involved in processing of the composites.

\subsubsection{Composites evaluation}

\subsubsection{Mechanical characterization}

The mechanical properties were determined by tensile and Izod impact tests. The dimensions of the samples were defined according to the American Society for Testing Materials (ASTM) standards.

\subsubsection{Tensile strengh test}

The tensile tests were performed according to ASTM D-638 on a universal testing machine (INSTRON E3000) with a load cell of $5000 \mathrm{~N}$, distance between claws of $115 \mathrm{~mm}$ and deformation rate of $5 \mathrm{~mm} \cdot \mathrm{min}^{-1}$. The widths and thicknesses of the specimens were measured using a caliper gauge (Mitutoyo, $\pm 0.001 \mathrm{~mm}$ ).

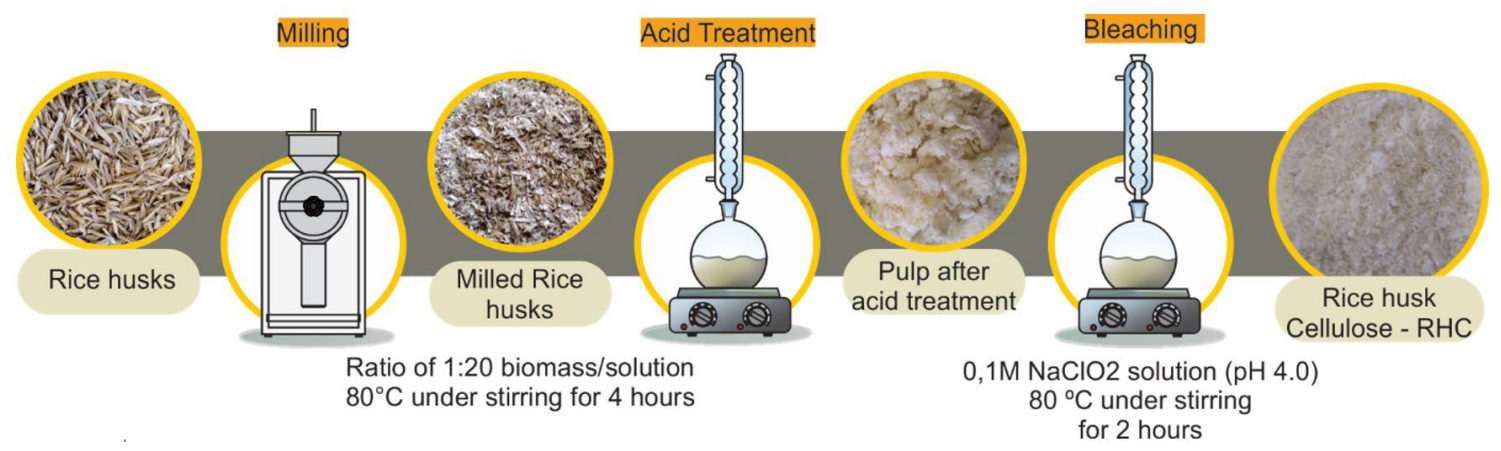

Figure 1. Flowchart of the RHC obtention process. 


\subsubsection{Izod impact test}

For the Izod impact tests (RESIL 25, from Ceast) the specimens were notched with a depth of $2.54 \pm 0.1 \mathrm{~mm}$, with minimum notch speed in accordance with ASTM D256. The tests were performed at room temperature.

\subsubsection{SEM analysis}

The fracture surfaces of the impacted specimens were observed by SEM, using a Jeol JSM- 6610LV equipament. A thin layer of gold was deposited on the material with metallizer.

\section{Results and Discussions}

\subsection{Cellulose characterization}

The in natura $\mathrm{RH}$ color is brown and after the first chemical treatment a brown-orange coloration was observed. After the bleaching, the material appears completely white (see Figure 1). These color changes are directly associated with the removal of non-cellulosic materials ${ }^{[8]}$. Thus, the white color observed in the final product was an indication of a high purity of the cellulosic material. However, further analysis is required, such as chemical composition, morphology, crystallinity and functional groups for its characterization $^{[9]}$.

\subsubsection{X-ray Diffraction (XRD)}

$\mathrm{X}$-ray diffraction was used to investigate the crystalline structure of RH before and after the chemical treatments used. In addition, microcrystalline cellulose (MCC) of commercial origin was analyzed for comparison. The diffractograms are represented in Figure 3.

It is reported in the literature, that cellulose have crystalline sctructure, due to Van der Waals' bonds, while hemicellulose and lignin have an amorphous characteristic ${ }^{[10]}$. As expected, natural rice husk has low crystallinity. There is an increase in the crystallinity of the samples according to the chemical treatments used, which may be related to the partial elimination of hemicellulose and lignin, indicating the efficiency of the procedure used to obtain the cellulose from rice husk. The peaks at approximately $16^{\circ}, 22^{\circ}$ and $34^{\circ}$ are characteristic of type I cellulose ${ }^{[9]}$, corresponding to the (101), (002) and (004) planes, respectively.

\subsubsection{Fourier Transformation Infrared Spectroscopy (FTIR)}

Figure 4 shows the spectra of the in natura rice husk, after acid extraction, RHC and MCC.

It is possible to observe in all spectra the presence of two major regions of absorbance ${ }^{[11]}$. The first region at high wavenumbers $\left(2700-3500 \mathrm{~cm}^{-1}\right)$ can be atribuited to different vibrations in polysaccharides and the second

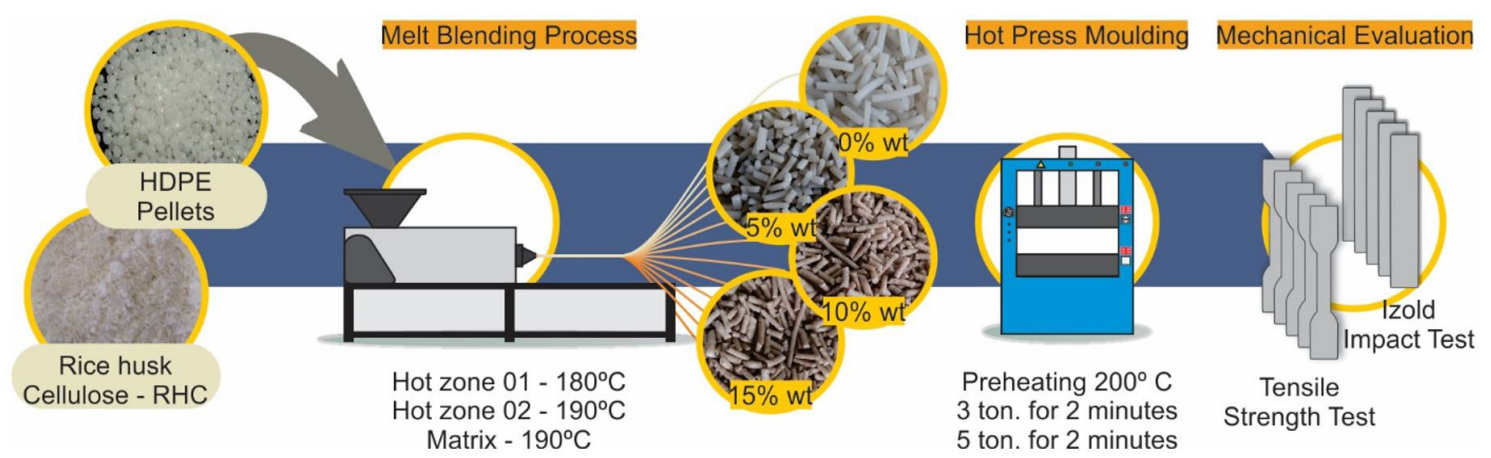

Figure 2. Flowchart of the composites processing.

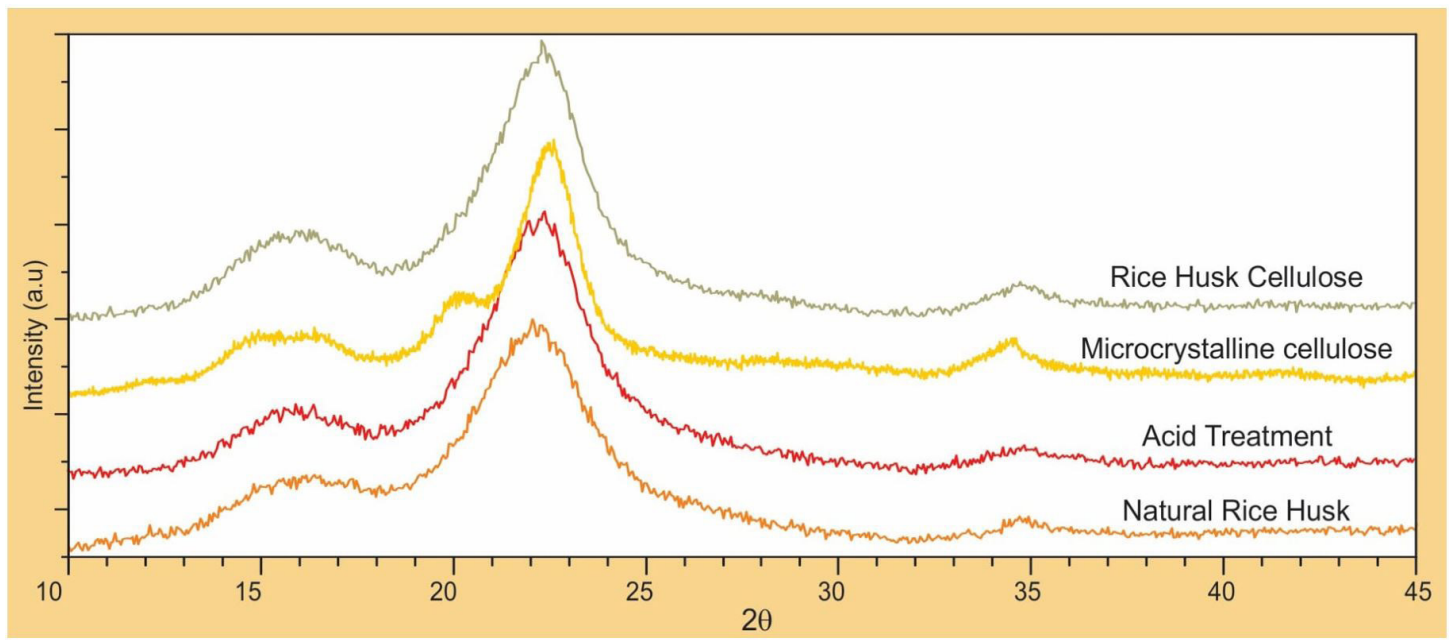

Figure 3. X-ray diffractograms of RH, RH after acid treatment, RHC and MCC. 
region at lower wavenumbers $\left(800\right.$ to $\left.1800 \mathrm{~cm}^{-1}\right)$ is typical assigned to cellulose ${ }^{[12]}$.

The peak in the region between $3500-3000 \mathrm{~cm}^{-1}$ confirms the presence of hydroxyl groups $(\mathrm{O}-\mathrm{H})$. For the $\mathrm{RHC}$, the increase in the area of this band indicates the presence of a greater number of $\mathrm{OH}$ groups ${ }^{[13]}$ and, consequently, an increase in RHC hydrophilicity.

The peak in $2921 \mathrm{~cm}^{-1}$ is observed in all spectra and it is due to the presence of $\mathrm{C}-\mathrm{H}$ stretching vibration in polysaccharides, evidencing the presence of cellulose and hemicellulose $\mathrm{e}^{[12,14]}$.

The bands in the range of $1700-1730 \mathrm{~cm}^{-1}$ are attributed to the vibration of acetyl and uronic groups of hemicellulose, or even to the ester linkage of carboxyl and p-coumaric acids in lignin ${ }^{[15]}$. In this region a peak reduction was observed, according to the chemical treatment sequences, thus confirming the partial removal of hemicellulose and lignin ${ }^{[11]}$. A small band was observed in the range of $1629-1621 \mathrm{~cm}^{-1}$, which can be attributed to the water absorbed in cellulose ${ }^{[12]}$. In general, the FTIR spectra have confirmed that RHC have a more open structure related to their greater wettability as the hemicellulose is dissolved or removed ${ }^{[13]}$. The band at $1170 \mathrm{~cm}^{-1}$ corresponds to the asymmetric stretching of the $\mathrm{C}-\mathrm{O}-\mathrm{C}$ bond of cellulose, hemicellulose and lignin ${ }^{[16]}$.
The bands observed at approximately $1030 \mathrm{~cm}^{-1}$ and at $800 \mathrm{~cm}^{-1}$ in the spectra correspond to the stretching bonds of $\mathrm{C}=\mathrm{O}$ in guaiacyl rings ${ }^{[17]}$ and $\mathrm{CH}$ deformations in cellulose $\mathrm{e}^{[15]}$, the latter one presents an increase in intensity as the treatment is performed, indicating an increase in cellulose content.

\subsubsection{SEM analysis}

Through the SEM images it was possible to investigate the changes in the structure of the $\mathrm{RH}$, as well as the cellulose, as shown in Figure 5.

The RH, Figure 5A, presented a more compact structure, with an irregular outer surface of hemicellulose, lignin, inorganic components and lumps or protuberances ${ }^{[18]}$, when compared to the RHC, Figure $5 \mathrm{~B}$ and $\mathrm{C}$, in which the bleached fibers had a fibrous and rough structure, with a mean diameter of $5 \mu \mathrm{m}^{[8]}$; also some particulates are observed, which can be related to residual material from the synthesis or even remained impurities. It was also observed the presence of some pores in the rough surface of the fibers, indicating that there may be an increase in the effective surface area for contact with the polymeric matrix, which contributes to the improvement of the mechanical properties.

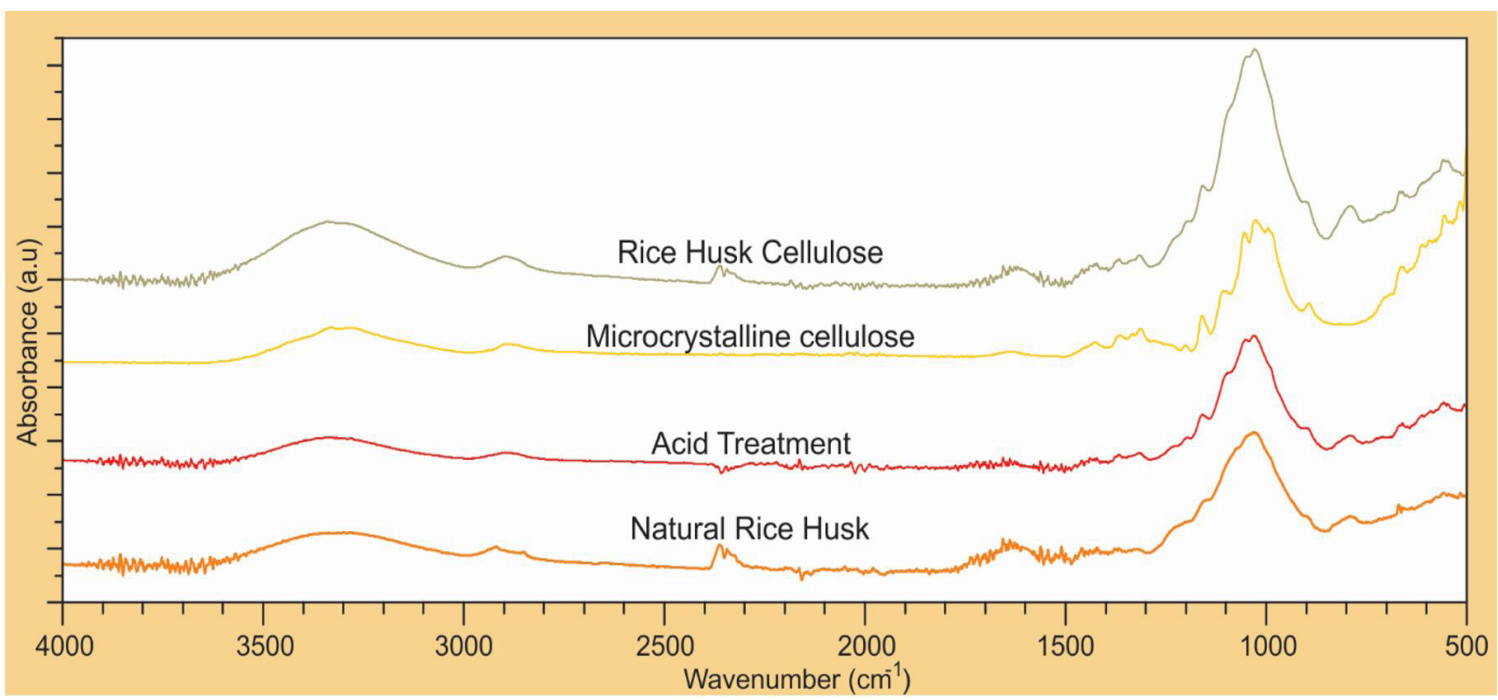

Figure 4. FTIR spectra of HR biomass, HR after the acid extraction, RHC and MCC.

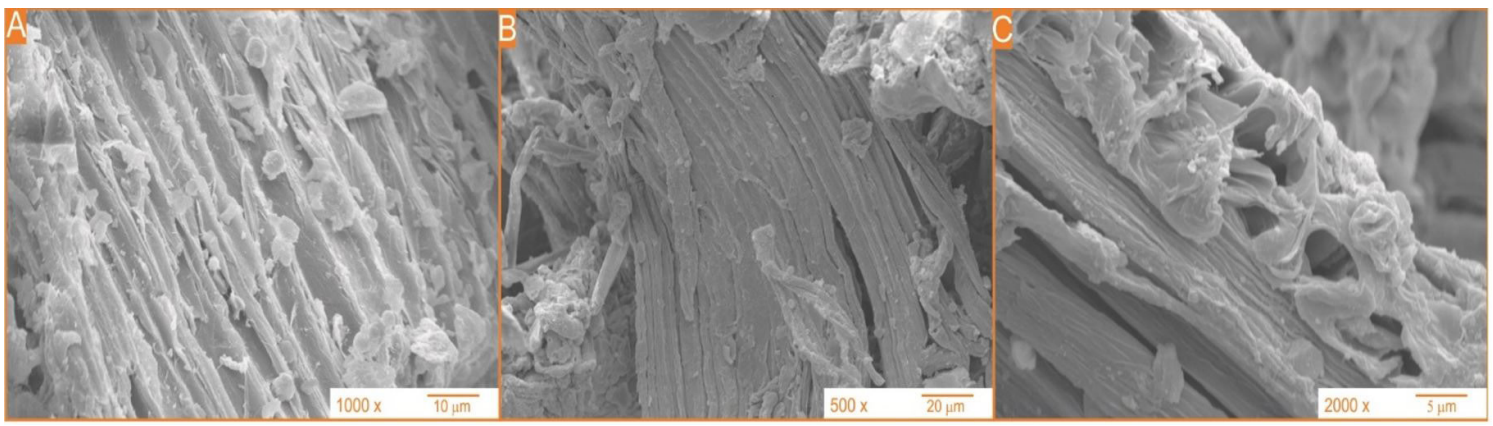

Figure 5. SEM micrographs of: (A) RH; (B) and (C) RHC. 


\subsection{Composites characterization}

\subsubsection{Mechanical characterization}

Figure 6 presents the graphs for the mechanical characterization.

\subsubsection{Tensile strength test}

In Figure 6A it is possible to observe that the modulus of elasticity of the composites presented different behaviors in relation to the HDPE. The HDPE composites have higher elastic modulus than pure HDPE. On the other hand, when analyzing the results obtained for composite materials prepared with different filler contents, it is verified that the values of elastic modulus presented by these materials have no significant difference. It is known that when a composite is reinforced with cellulose, the tensile modulus of the polymer compound can improve considerably. However, this property change will also depend on the strength and effectiveness of the interfacial adhesion between cellulose and matrix ${ }^{[19]}$, which can be improved with prior treatment and also of the amount of filler used. Low contents of cellulose can form regions of high mechanical stress, by a not so homogeneously dispersed mixture, resulting in a decrease in elastic modulus. Higher contents of cellulose, in its turn, can result in a better distribuition of stresses, and thus greater modulus ${ }^{[20]}$.

This small increase in the values of elastic modulus indicates a low interaction between the polymer and the matrix, and this can be explained by its lack of chemical affinity, since the HDPE is apolar and the cellulose is known for its polarity, as can be confirmed by FTIR.

\subsubsection{Izod impact test}

In Figure 6B it is observed that HDPE presented an average impact resistance of $178.65 \mathrm{~J} / \mathrm{m}$, higher than the composites with 5,10 and $15 \mathrm{wt} \%$ of cellulose, with values of $172.99 \mathrm{~J} / \mathrm{m}, 162.54 \mathrm{~J} / \mathrm{m}$ and $126.36 \mathrm{~J} / \mathrm{m}$, respectively. Its already established in literature that HDPE has a high Izod impact strength, which is decreased when reinforced with vegetable fibers ${ }^{[21]}$.
Considering the standard deviations, it can be affirmed that the addition of up to $10 \mathrm{wt} \%$ of RHC does not promote significant reductions in the impact resistance when compared to pure HDPE. The HDPE $/ 15 \mathrm{wt} \% \mathrm{RHC}$ presented a greater decrease impact resistance, breaking more easily, and also making it a material with greater rigidity lower tenacity. This can be explained since the introduction of reinforcements can promote stress concentration, generating the presence of micro-interfacial voids, which make the microcracks to propagate easily in the composite, and then reducing impact resistance ${ }^{[22]}$. Also, RH is fragile and therefore, have a low capacity to absorb energy during the propagation of the fracture. Similar results of decrease in impact strength with increasing cellulose content was observed in literature ${ }^{[19]}$, who reported an increase in its brittleness due to large amounts of cellulose in a HDPE matrix. This decrease in impact strength of the polymer matrix can also be reverted by the use of impact modifiers, which improve the matrix / reinforcement interface.

\subsubsection{SEM analysis}

Its well established that interfacial adhesion matrix/filler and dispersion of the filler in the polymer matrix are determining factors in mechanical properties of any composite material ${ }^{[23]}$. In this way, the mechanical results can be confirmed to the observed in SEM analysis. Figure 7 presents SEM micrographs obtained from the fracture surface of the samples after the Izod impact tests were performed.

The micrographs revealed a heterogeneous distribution of the RHC in HDPE matrix, with RHC presenting different morphologies, such as rods-like structures, particulates and also agglomerates. These different morphologies can be justified by the fragmentation of RHC during the composites extrusion and the agglomeraion due the greater affinity of cellulose with itself than with the matrix.

Considering the amount of RHC used represents most of the composite volume, we can affirm that it was possible to achieve a good adhesion between the phases, with the RHC distributed in the polymer, contributing to the increase of the elastic modulus when comparing to the HDPE. However, it is possible to observe regions of detachment of the RHC

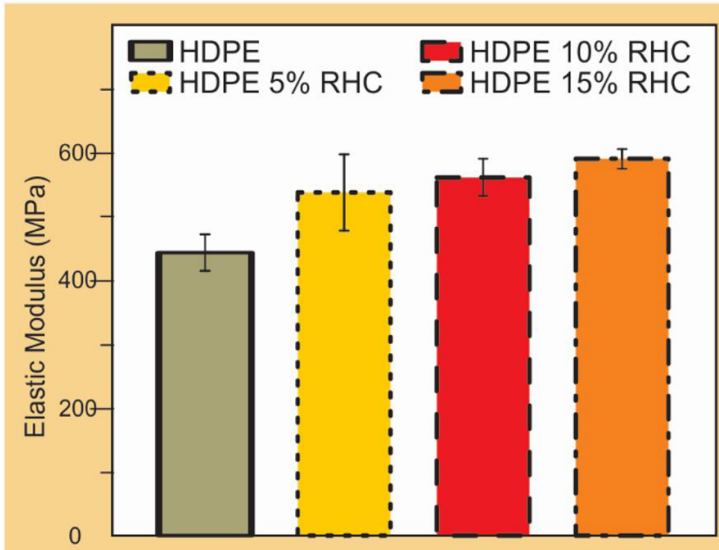

(A)

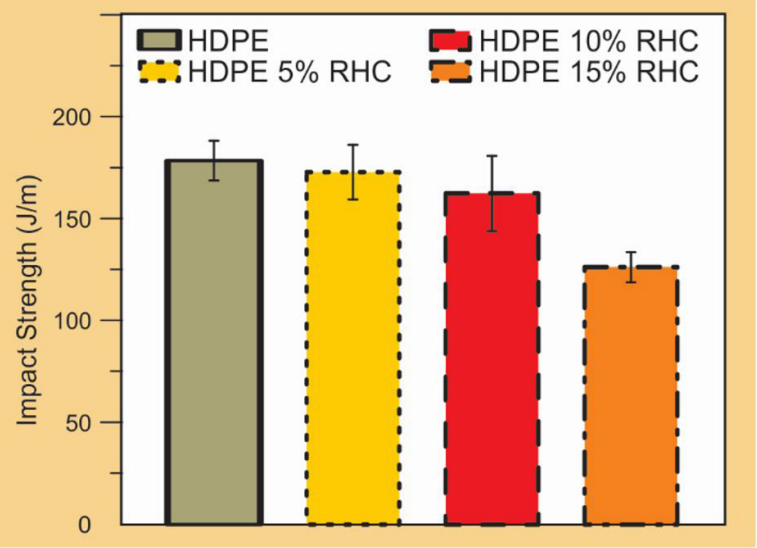

(B)

Figure 6. (A) Elastic modulus and (B) Impact strength for pure HDPE, HDPE 5wt $\%$ RHC, HDPE 10wt $\%$ RHC and HDPE $15 w t \%$ RHC composites. 


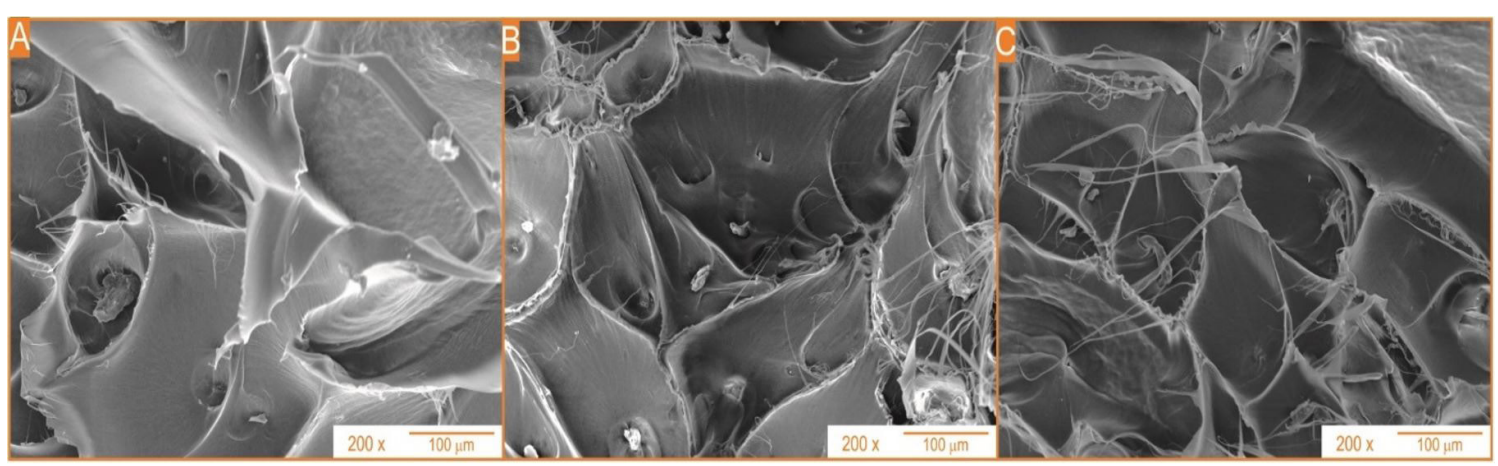

Figure 7. SEM micrographs of (A) HDPE $5 \mathrm{wt} \%$ RHC, (B) HDPE $10 \mathrm{wt} \%$ RHC and (C) HDPE $15 \mathrm{wt} \%$ RHC.

from the matrix, forming voids. The more RHC was used, the more detachments could be perceived, due to the higher amount of RHC. In the same way, more voids are formed. The appearance of defects as voids with the increase in the amount of RHC used, justifies the results obtained by the impact resistance tests.

All observed fracture surfaces are rough, indicating that the addition of RHC did not change the fracture behavior of the polymeric matrix, which remained plastic.

\section{Conclusions}

Considering that the results of FTIR, XRD and SEM are in agreement with the literature, we can say that the treatment used was efficient for obtaining cellulose from RH biomass.

The addition of RHC in the HDPE polymer matrix had good effect on the elastic modulus of the composites, as we can confirm by the improvement in the rigidity of the composites when compared to the pure matrix, but without significant changes for higher contents of RHC. The impact strength have decreased as the RHC content increase in the polymeric matrix. Micrographs obtained by MEV from the fractured surface obtained by impact test of the composites, revealed some adherence between RHC-matrix. In this context, the results obtained for the HDPE composites with the addition of RHC present a superiority over the pure matrix and thus create the possibility of its use in composites and an alternative to use this residue.

\section{Acknowledgements}

The authors would like to acknowledge the CAPES (Coordination for the Improvement of Higher Education Personnel), the Centro de Microscopia Eletrônica do Sul (CEMESUL) of Federal University of Rio Grande, the Department of Materials Engineering of Federal University of São Carlos (DEMa/UFSCar) and the Laboratório de Materiais Poliméricos (LaPol) of Federal University of Rio Grande do Sul (UFRGS) for the use of infrastructure.

\section{References}

1. Ligowski, E., Santos, B. C., \& Fujiwara, S. T. (2015). Materiais compósitos a base de fibras da cana-de-açúcar e polímeros reciclados obtidos através da técnica de extrusão
TT - Composite materials based on fibers from sugar cane and recycled polymers obtained by extrusion technique. Polimeros: Ciência e Tecnologia, 25(1), 70-75. http://dx.doi. org/10.1590/0104-1428.1605.

2. Yang, H. S., Kim, H. J., Park, H. J., Lee, B. J., \& Hwang, T. S. (2006). Water absorption behavior and mechanical properties of lignocellulosic filler-polyolefin bio-composites. Composite Structures, 72(4), 429-437. http://dx.doi.org/10.1016/j. compstruct.2005.01.013.

3. Food and Agriculture Organization of the United Nations FAO. (2018). Seguimiento del mercado del arroz de la FAO (Informe FAO de actualización de precios del arroz, Vol. 21, No. 1,10 p.). Rome: FAO. Retrieved in 2019, June 22, from http://www.fao.org/3/I9243ES/19243es.pdf

4. Santos, P., \& Costa, A. C. S. (2013). X-ray diffraction and thermal analysis of kaolins particle size fractions. Semina. Ciências Exatas e Tecnológicas, 34(1), 9-22. http://dx.doi. org/10.5433/1679-0375.2013v34n1p9.

5. Chandrasekhar, S., Satyanarayana, K. G., Pramada, P. N., Raghavan, P., \& Gupta, T. N. (2003). Processing, properties and applications of reactive silica from rice husk - an overview. Journal of Materials Science, 38(15), 3159-3168. http://dx.doi. org/10.1023/A:1025157114800.

6. Wu, G., Qu, P., Sun, E., Chang, Z., Xu, Y., \& Huang, H. (2015). Physical, chemical, and rheological properties of rice husks treated by composting process. BioResources, 10(1), 227-239. Retrieved in 2019, June 22, from https://bioresources.cnr.ncsu. edu/resources/physical-chemical-and-rheological-propertiesof-rice-husks-treated-by-composting-process/

7. Campos, A., Teodoro, K. B. R., Marconcini, J. M., Mattoso, L. H. C., \& Martins-Franchetti, S. M. (2011). Efeito do tratamento das fibras nas propriedades do biocompósito de amido termoplástico/policaprolactona/sisal. Polímeros, Ciência e Tecnologia, 21(3), 217-222. http://dx.doi.org/10.1590/s010414282011005000039.

8. Johar, N., Ahmad, I., \& Dufresne, A. (2012). Extraction, preparation and characterization of cellulose fibres and nanocrystals from rice husk. Industrial Crops and Products, 37(1), 93-99. http://dx.doi.org/10.1016/j.indcrop.2011.12.016.

9. E1 Halal, S. L. M., Colussi, R., Deon, V. G., Pinto, V. Z., Villanova, F. A., Carreño, N. L. V., Dias, A. R. G., \& Zavareze, E. R. (2015). Films based on oxidized starch and cellulose from barley. Carbohydrate Polymers, 133, 644-653. http:// dx.doi.org/10.1016/j.carbpol.2015.07.024. PMid:26344323.

10. Prado, K. S., \& Spinacé, M. A. S. (2015). Characterization of Fibers from Pineapple's Crown, Rice Husks and Cotton Textile Residues. Materials Research, 18(3), 530-537. http:// dx.doi.org/10.1590/1516-1439.311514. 
11. Jonoobi, M., Harun, J., Shakeri, A., Misra, M., \& Oksmand, K. (2009). Chemical composition, crystallinity, and thermal degradation of bleached and unbleached kenaf bast (Hibiscus cannabinus) pulp and nanofibers. BioResources, 4(2), 626-639. Retrieved in 2019, June 22, from https://bioresources.cnr.ncsu. edu/resources/chemical-composition-crystallinity-and-thermaldegradation-of-bleached-and-unbleached-kenaf-bast-hibiscuscannabinus-pulp-and-nanofibers/

12. Hospodarova, V., Singovszka, E., \& Stevulova, N. (2018). Characterization of cellulosic fibers by FTIR spectroscopy for their further implementation to building materials. American Journal of Analytical Chemistry, 09(06), 303-310. http://dx.doi. org/10.4236/ajac.2018.96023.

13. Rong, M. Z., Zhang, M. Q., Liu, Y., Yang, G. C., \& Zeng, H. M. (2001). The effect of fiber treatment on the mechanical properties of unidirectional sisal-reinforced epoxy composites. Composites Science and Technology, 61(10), 1437-1447. http:// dx.doi.org/10.1016/S0266-3538(01)00046-X.

14. Adel, A. M., Abd El-Wahab, Z. H., Ibrahim, A. A., \& Al-Shemy, M. T. (2010). Characterization of microcrystalline cellulose prepared from lignocellulosic materials. Part I. Acid catalyzed hydrolysis. Bioresource Technology, 101(12), 4446-4455. http:// dx.doi.org/10.1016/j.biortech.2010.01.047. PMid:20185300.

15. Pelissari, F. M., Sobral, P. J. A., \& Menegalli, F. C. (2014). Isolation and characterization of cellulose nanofibers from banana peels. Cellulose (London, England), 21(1), 417-432. http://dx.doi.org/10.1007/s10570-013-0138-6.

16. Rosa, M. F., Medeiros, E. S., Malmonge, J. A., Gregorski, K. S., Wood, D. F., Mattoso, L. H. C., Glenn, G., Orts, W. J., \& Imam, S. H. (2010). Cellulose nanowhiskers from coconut husk fibers: effect of preparation conditions on their thermal and morphological behavior. Carbohydrate Polymers, 81(1), 83-92. http://dx.doi.org/10.1016/j.carbpol.2010.01.059.

17. Silvério, H. A., Flauzino Neto, W. P., Dantas, N. O., \& Pasquini, D. (2013). Extraction and characterization of cellulose nanocrystals from corncob for application as reinforcing agent in nanocomposites. Industrial Crops and Products, 44, 427-436. http://dx.doi.org/10.1016/j.indcrop.2012.10.014.

18. Oliveira, J. P., Bruni, G. P., Lima, K. O., Halal, S. L. M. E., Rosa, G. S. D., Dias, A. R. G., \& Zavareze, E. D. R. (2017). Cellulose fibers extracted from rice and oat husks and their application in hydrogel. Food Chemistry, 221, 153-160. http:// dx.doi.org/10.1016/j.foodchem.2016.10.048. PMid:27979125.

19. Boran, S. (2016). Mechanical, morphological, and thermal properties of nutshell and microcrystalline cellulose filled high-density polyethylene composites. BioResources, 11(1), 1741-1752. http://dx.doi.org/10.15376/biores.11.1.1741-1752.

20. Spadetti, C., Silva, E. A., Fo., Sena, G. L., \& Melo, C. V. P. (2017). Propriedades térmicas e mecânicas dos compósitos de polipropileno pós-consumo reforçados com fibras de celulose. Polimeros, Ciência e Tecnologia, 27(spe), 84-90. http://dx.doi. org/10.1590/0104-1428.2320.

21. Morais, J. A., Gadioli, R., \& De Paoli, M.-A. (2016). Curaua fiber reinforced high-density polyethylene composites: effect of impact modifier and fiber loading. Polímeros, Ciência e Tecnologia, 26(2), 115-122. http://dx.doi.org/10.1590/01041428.2124

22. Poletto, M., \& Zattera, A. J. (2017). Mechanical and dynamic mechanical properties of polystyrene composites reinforced with cellulose fibers : coupling agent effect. Journal of Thermoplastic Composite Materials, 30(9), 1242-1254. http:// dx.doi.org/10.1177/0892705715619967.

23. Mathew, A. P., Oksman, K., \& Sain, M. (2005). Mechanical properties of biodegradable composites from poly lactic acid (PLA) and microcrystalline cellulose (MCC). Journal of Applied Polymer Science, 97(5), 2014-2025. http://dx.doi. org/10.1002/app.21779.

Received: June 22, 2019

Revised: Nov. 20, 2019

Accepted: Feb. 11, 2020 